\title{
Evaluation of the deep vein recanalisation and function after low molecular weight heparin (calcium nadroparine) therapy of deep vein thrombosis. Preliminary report
}

\author{
Piotr A. Kazmierski \\ Department of Vascular, General and Oncological Surgery, Copernicus Memorial Hospital, Lodz, Poland
}

\begin{abstract}
Introduction. The standard treatment for acute episode of deep vein thrombosis (DVT) included at least five days administration of unfractionated heparin followed by oral anticoagulants (OAs) in the subsequent months. In the early 2000s the use of low-molecular-weight heparins (LMWH) was recommended and validated as the equivalent for the standard therapy of acute episode of DVT. The aim of this study was to evaluate the patency of thrombotic venous segments and indirectly the function of valves after therapy with calcium nadroparine in the 10 days ambulatory treatment and three-month secondary prophylaxis of acute DVT.
\end{abstract}

Material and methods. The study group consisted of 50 patients ( 10 females and 40 males), aged 33 to 92 years (mean age 62.3 years) with first episode of acute, symptomatic deep vein thrombosis of the lower extremities, below the inguinal ligament, who were followed-up during their 10 days ambulatory treatment and three-month secondary prophylaxis with calcium nadroparine. Each patient had clinical examinations and ultrasound of the veins of the lower extremities, using the colour-coded power Doppler ultrasound (CDU) performed by the same experienced physician, using TOSHIBA device (linear probe 6- $12 \mathrm{MHz}$ ), on day I and 10 of the treatment period and after I and 3 months of secondary prophylaxis phase. All patients underwent the following laboratory tests: before treatment the coagulation profile, blood group and complete blood count; the control platelet count was performed after 7 to 10 days of $L M W H$ treatment, and then every 10 days.

Results. The thrombosis was revealed in the femoro-popliteal segment in 35 (70\%) subjects and below the knee in the remaining 15 (30\%) patients. There was no case of DVT recurrence, thromboembolic event or death in patients who received LMWH therapy during the 3-month follow-up period. No adverse effects of the treatment were observed. CDU revealed the complete venous recanalisation in 40 (80\%) patients and partial recanalisation with residual thrombi and/or wall thickening in the remaining 10 (20\%) subjects. After the 3-month treatment period deep vein reflux was not observed in 30 (60\%) patients, whereas the remaining 20 (40\%) were diagnosed with only an insignificant reflux (lasting I-2 seconds).

Conclusions. The calcium nadroparine therapy is an efficient, safe and well tolerated method of ambulatory treatment and secondary prophylaxis of the acute, symptomatic deep vein thrombosis of the lower extremities. Further, longer and prospective, multi-centre studies are required for better evaluation of the early and late results of DVT treatment with $L M W H$. They would allow investigating their effect on venous recanalisation, its function and prevention of post-thrombotic syndrome.

Key words: deep vein thrombosis, low-molecular-weight heparins, secondary prophylaxis of DVT, post-thrombotic syndrome, valvular incompetence of veins

Acta Angiol 2015; 21, 3: 75-82

Address for correspondence: Piotr Kazmierski, Department of Vascular, General and Oncological Surgery, Copernicus Memorial Hospital, Pabianicka 62, 93-I35 Lodz, e-mail: avel5I@wp.pl 


\section{Introduction}

The standard treatment for acute episode of deep vein thrombosis (DVT) was administration of unfractionated heparin (UFH) for at least five days followed by secondary prophylaxis with oral anticoagulants (OAs) for a variable period ranging from 3 to 9 months $[1-2]$. Such therapy is burdened with many inconveniences for both the patient and the physician. There is also a risk of significant and life-threatening therapy-related complications. The late effects of therapy, such as chronic venous insufficiency $(\mathrm{CVI})$ and post-thrombotic syndrome (PTS) are also unsatisfactory. In 2001 the American College of Chest Physicians (ACCP) recommended the use of low-molecular-weight heparins (LMWH) in the therapy of acute episode of DVT [3]. Many clinical trials proved that therapy with LMWH is efficient and safe both in the treatment and secondary prophylaxis of acute deep vein thrombosis, which may successfully be performed in the ambulatory setting [4-17]. The administration of $L M W H$ significantly reduces the risk of complications and the ambulatory treatment costs, with relatively better outcome concerning the recurrence of venous thrombosis and pulmonary embolism [ $|8-2|]$. The latest reports discuss the influence the LMWH has on the recanalisation of the thrombotic-occluded veins and indicate the reduction of valvular incompetence rate, secondary to venous thrombosis [22-42].

The aim of this study was to evaluate the patency of thrombotic-occluded venous segments, below the inguinal ligament and, indirectly, the function of valves after therapy with calcium nadroparine in the 10 days ambulatory treatment and three-month secondary prophylaxis of acute deep vein thrombosis. The secondary aim was to evaluate the rate of thrombosis recurrences, incidence of pulmonary embolism and treatment complications requiring its discontinuation and/or patient readmission.

\section{Material and methods}

The study group consisted of 50 patients ( $10 \mathrm{fe}-$ males and 40 males), aged 33 to 92 years (mean age 62.3 years) with first episode acute symptomatic deep vein thrombosis of the lower extremities, below the inguinal ligament, who were treated with calcium nadroparine preparations. The inclusion criteria for the treatment and follow-up included: adult patients (aged $>18$ years), with symptoms of acute DVT lasting no longer than 14 days, good general condition, no complete immobilisation required, no clinical symptoms of pulmonary embolism, no increased risk of bleeding and no contraindications to $L M W H$. The exclusion criteria were: pregnancy, active neoplasm, recent (30 days) cen- tral nervous system (CNS) surgery, CNS trauma in the previous 3 months, elective surgery planned in the following 3 months, thrombocytopenia, allergy to heparin, active treatment with thrombolytic therapy, taking dual antiplatelet drugs or coumarin derivatives and previous episode of thromboembolism. Each patient provided written informed consent to the participation in the study. Each patient received a subcutaneous injections of therapeutic dose of calcium nadroparine for 10 days $(0.1 \mathrm{~mL} / 10 \mathrm{~kg}$ body weight, twice daily), which was followed by half that dose for 3 months $(0.1 \mathrm{~mL} / 10 \mathrm{~kg}$ body weight, once daily). In the last 3 month period of treatment (after LMWH therapy) oral anticoagulant Acenokumarol (Syncumar) was administered and dosed according to the international normalised ratio (INR) values. During calcium nadroparine-therapy clinical and colour-duplex ultrasound (CDU) examination was performed by the same qualified medical investigator (P.K.) at the initial and subsequent scheduled follow-up visits. CDU Toshiba ( $\mathrm{N}$ of model, 6-12 MHz linear probe) assessment of the whole lower limb veins was performed on days $I$ and $I 0$ of the treatment period and after I and 3 months. All patients were examined while standing, in supine and prone position. The examination protocol included the ultrasound evaluation (B-mode, cross-sectional and longitudinal) of each venous segment of both lower extremities (compression trial and measurement of wall thickness). The morphology of the venous walls, valves, as well as structure and echogenicity of thrombi were evaluated. The cross-section area of the thrombotic venous segments and visible thrombi were measured to assess the patency degree of the vessel. Compression index and the measurement of the thrombi thickness allowed for the evaluation of the recanalisation degree and thrombus reorganisation. The pulsed wave Doppler was used to evaluate the flow spectrum and its changes with respiration and compression manoeuvres. The valve competence was assessed during proximal and distal compression and Valsalva manoeuvre. The retrograde flow (reflux) lasting for more than I second was recognised as sign of valvular incompetence. The measurement of time, velocity and flow volume after thigh and calf compression allowed for the evaluation of the visible venous reflux degree. The venous reflux index (VRI) was calculated to objectivise the latter. After one-day hospitalisation in the Department of Vascular, General and Oncologic Surgery the patients were dismissed and treated in the ambulatory setting under the strict supervision of the physician of the Out-patient Clinic for Peripheral Vascular Diseases. Each patient had the following laboratory tests performed before the LMWH treatment period: coagulation profile (prothrombin time - PT, thrombin time - TT, activated partial 
thromboplastin time - APTT, fibrinogen), blood group and complete blood count (including platelet count). The control platelet count was performed after 7 to 10 days of LMWH treatment, and then every 10 days. After receiving the first dose of $L M W H$ in the hospital, the patients were instructed how to inject the medication subcutaneously, and they were to perform such injections on their own at home. All patients were also advised to wear class II (25-35 mm Hg) compression stockings in day time. Each patient was advised and received written information about the need to report to the attending physician any possible adverse event. Table I presents the demographic characteristics of the study group and the distribution of risk factors for venous thromboembolism.

\section{Results}

The CDU examination performed prior to starting the treatment revealed an acute venous thrombosis in the femoro-popliteal segment in 35 subjects (70\%) and calf thrombosis in the remaining 15 patients $(30 \%)$. In 30 patients $(60 \%)$ the thrombosis was localised in the right lower extremity, in $20(40 \%)$ on the left side. The CDU examination performed 10 days and I month after the beginning of the treatment revealed no thrombosis progression. Conversely, all patients (100\%) manifested gradual recanalisation of thrombotic deep vein segments. The speed of thrombus recanalisation and reorganisation was different: for example, the distal segments of thrombotic veins and single stem vessels were the first to regain patency. In the early phase the flow channel appeared near the vessel wall, which was well visible in the Power Doppler mode (Fig. I-3).

The recanalisation process was longer in patients, with more extensive thrombosis, (e.g. concomitant proximal and distal thrombosis and with anatomical variant of double venous stem) and in patients who received LMWH relatively late after the onset of clinical symptoms. After three months of calcium nadroparine therapy, the recanalisation of the veins was evaluated and qualified as total in $40(80 \%)$ patients or partial (residual thrombi and/or wall thickening) in the remaining $10(20 \%)$ subjects. The partial recanalisation was observed mainly in patients with extensive venous thrombosis or patients with several venous stems involved, or delayed treatment in relation to the onset of clinical symptoms. In 30 (60\%) subjects no reflux in the recanalised deep veins was detected. The remaining $20(40 \%)$ patients showed deep vein reflux of $\mathrm{I}-2$-second duration. This group was dominated by patients with slower recanalisation rate and with residual wall lesions. No recurrence of deep vein thrombosis was
Table I. Demographic and DVT risk factors of the examined group

\begin{tabular}{|c|c|}
\hline Demographic and risk factors & $\mathrm{N}(\%)$ \\
\hline Sex & $N=50(100)$ \\
\hline Male & $40(80)$ \\
\hline Female & $10(20)$ \\
\hline Age & $62.2 \pm 9.2$ \\
\hline \multicolumn{2}{|l|}{ Age over 60} \\
\hline Yes & $26(52)$ \\
\hline No & $24(48)$ \\
\hline \multicolumn{2}{|l|}{ Congestive heart failure } \\
\hline Yes & $12(24)$ \\
\hline No & $38(76)$ \\
\hline \multicolumn{2}{|l|}{ Varicose veins } \\
\hline Yes & $19(38)$ \\
\hline No & $31(62)$ \\
\hline \multicolumn{2}{|l|}{ Body mass index $\left[\mathrm{kg} / \mathrm{m}^{2}\right]$} \\
\hline $18.5-24.9$ & $37(74)$ \\
\hline$>25$ & $13(26)$ \\
\hline \multicolumn{2}{|l|}{ Major surgery } \\
\hline Yes & $6(12)$ \\
\hline No & $44(88)$ \\
\hline \multicolumn{2}{|c|}{ Patients confirmed to bed $>72 \mathrm{hrs}$} \\
\hline Yes & $4(8)$ \\
\hline No & $46(92)$ \\
\hline \multicolumn{2}{|l|}{ Immobilizing plaster cast } \\
\hline Yes & $3(6)$ \\
\hline No & $47(94)$ \\
\hline \multicolumn{2}{|c|}{ Inflammatory bowel disease } \\
\hline Yes & $2(4)$ \\
\hline No & $48(96)$ \\
\hline \multicolumn{2}{|l|}{ Long travel > $8 \mathrm{hrs}$} \\
\hline Yes & $5(10)$ \\
\hline No & $45(90)$ \\
\hline \multicolumn{2}{|c|}{ Combined oral contraceptive/HRT } \\
\hline Yes & $3(6)$ \\
\hline No & $7(14)$ \\
\hline
\end{tabular}

${ }^{\mathrm{a}}$ Hormonal replacement therapy

observed during the three-month follow-up period of the patients treated with calcium nadroparine. No episodes of pulmonary embolism or deaths were noted. No adverse effects (major bleeding or heparin induced thrombocytopenia - HIT) were observed in the patients treated with calcium nadroparine. No patient was qualified for repeated hospitalisation during the 


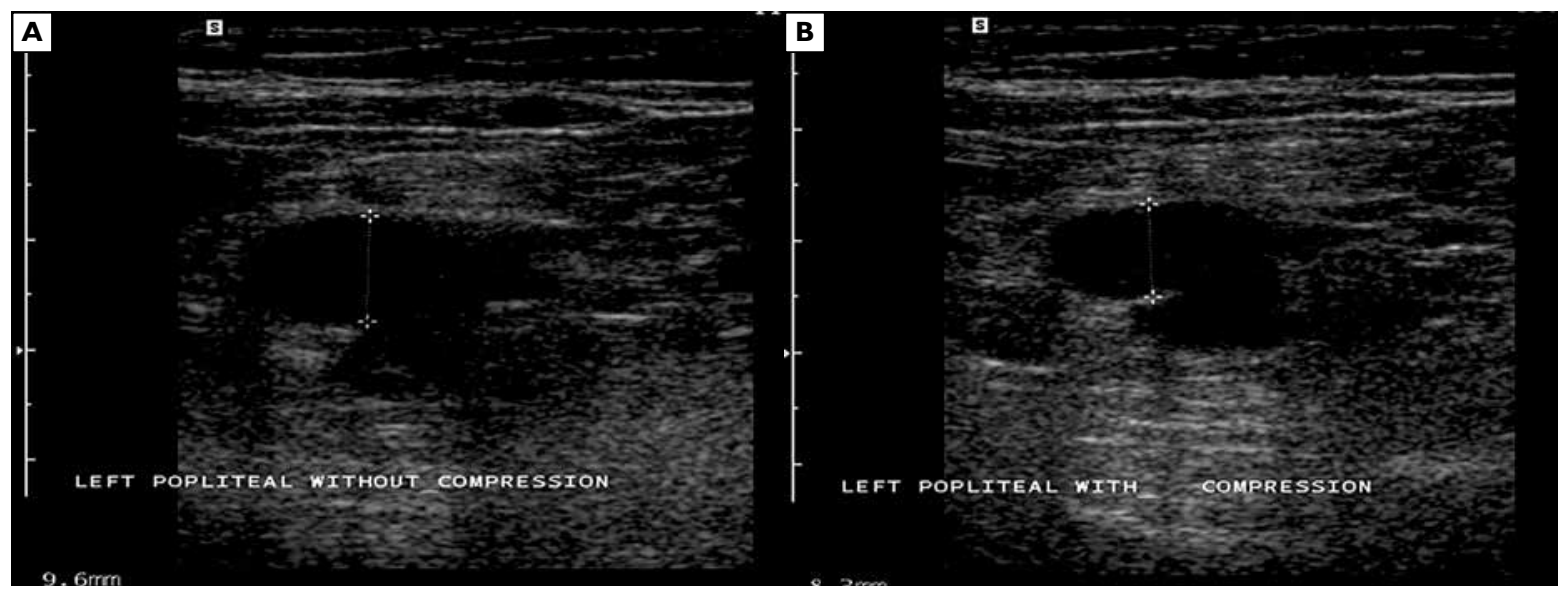

Figure IA. Ultrasound of the left popliteal vein (without compression). Day I acute thrombosis (vein over the artery); B. Ultrasound of the left popliteal vein (compression). Day I, acute thrombosis, thrombus size $8.3 \mathrm{~mm}$ (vein over the artery)

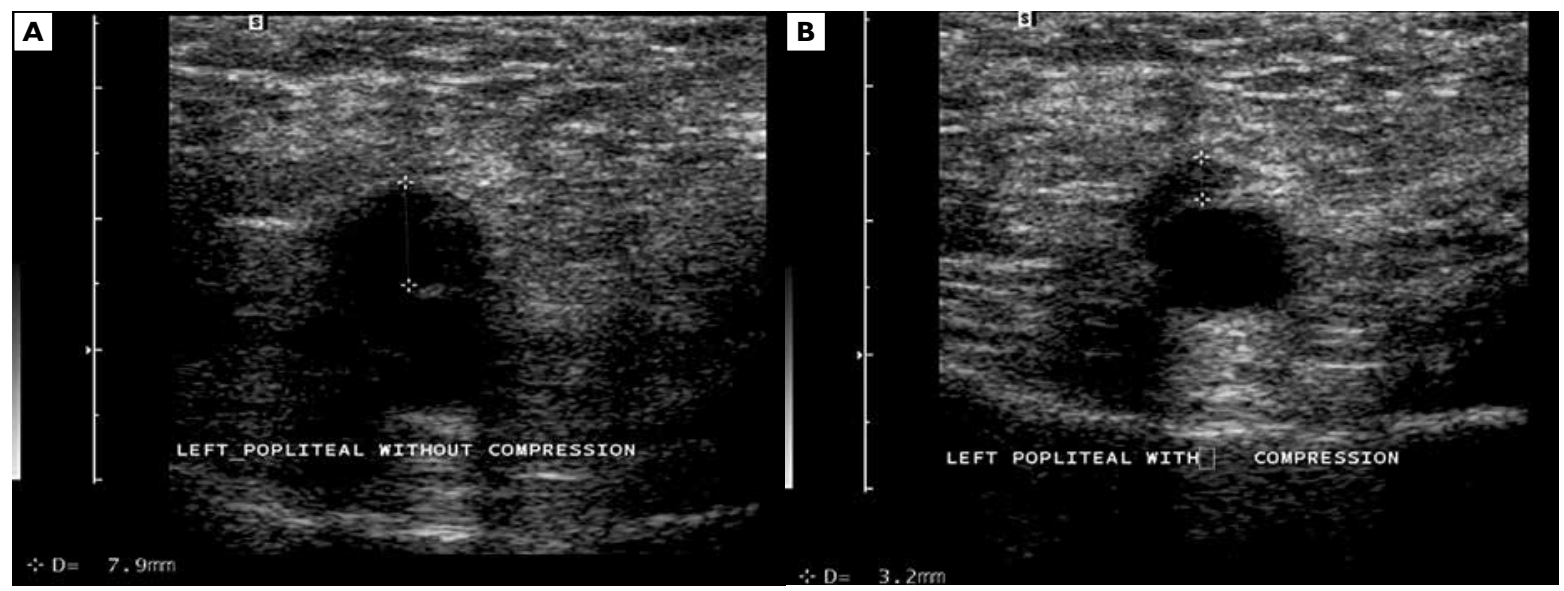

Figure 2A. Ultrasound of the popliteal vein (without compression). Day 30 (vein over the artery); B. Ultrasound of the popliteal vein (compression). Day 30, high-grade recanalization, residual thrombus size $3.2 \mathrm{~mm}$ (vein over the artery)

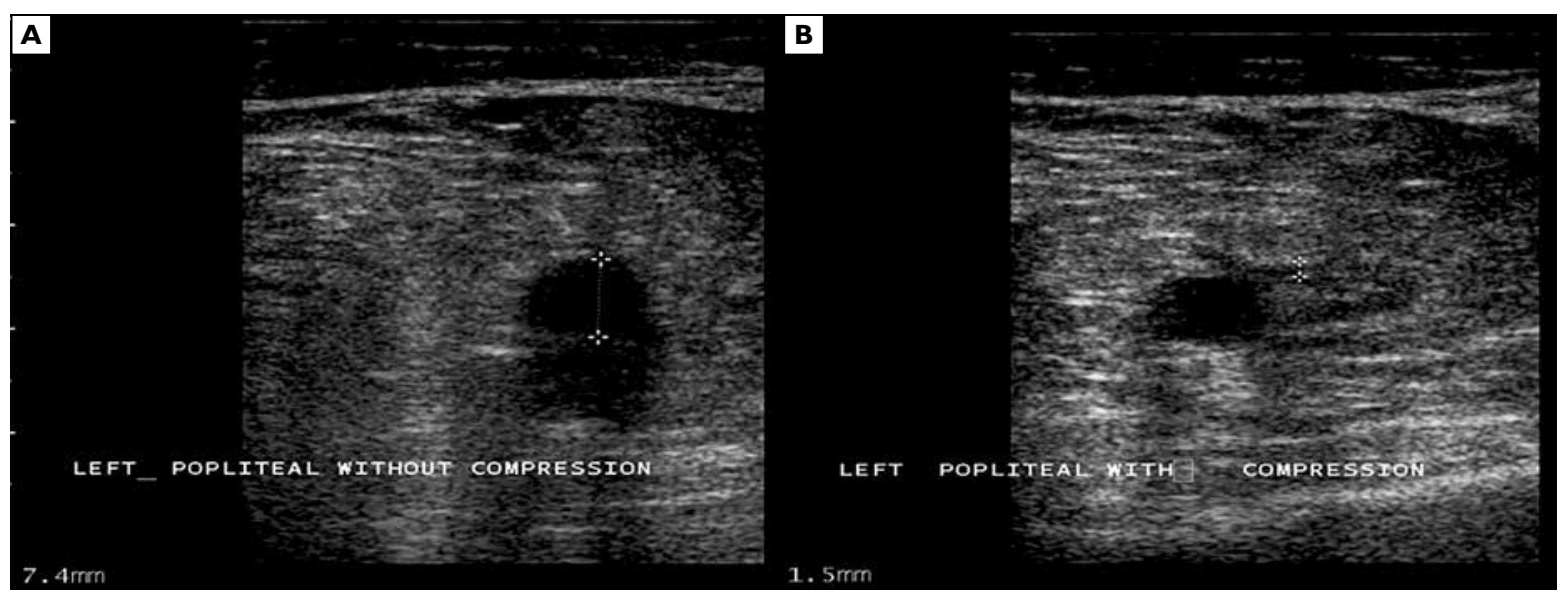

Figure 3A. Ultrasound of the popliteal vein (without compression). Day 90 (vein over the artery); B. Ultrasound of the popliteal vein (compression). Day 90, complete recanalization; artery is the sole visible vessel, the vein is completely compressed (between crosses) 
secondary prophylaxis phase. There was no reason to discontinue calcium nadroparine therapy for any other reason. Small haematomas in the injection site were observed in $8(16 \%)$ patients. Seven (14\%) patients reported slight pain, II (22\%) reported burning sensation of the skin in the injection site, and $3(6 \%)$ the inconvenience of such therapy (Tab. 2).

\section{Discussion}

Deep vein thrombosis (DVT) of the lower extremities constitutes a relevant vascular disease with serious repercussions from the clinical and epidemiological point of view. The annual incidence of venous thromboembolism (VTE) in USA is estimated at 500 thousand, whereas 170/100,000 new cases are registered each year in the Western European countries [34, 35]. Acute DVT may cause early complications such as pulmonary embolism (PE), which is responsible for 200 thousand deaths annually only in the United States and for $10 \%$ of all in-hospital deaths in Great Britain and Sweden [34, 36, 37]. Late sequelae, such as post-thrombotic syndrome (PTS), and related chronic venous insufficiency (CVI), occur in 20 to $50 \%$ of patients after acute DVT. It often affects young adults in the working age. The incidence of lower leg ulcers is estimated at $300 / 100,000$, with at least $25 \%$ of them being secondary to deep vein thrombosis [38-40]. The total treatment cost of CVI in the Western European countries is estimated at $600-900$ million Euro, which makes up of $\mathrm{I}-2 \%$ of the total healthcare budget of the European Union [4I]. Correctly managed anticoagulation constitutes the best method of treatment and secondary prophylaxis of acute DVT, and aims at preventing deaths and VTE recurrences, as well as pulmonary hypertension and post-thrombotic syndrome. The standard DVT treatment consisted of at least five days course of the administration of unfractionated heparin, with subsequent treatment with oral anticoagulants. The studies concerning the efficacy and safety of low-molecular-weight heparins in VTE proved their superiority over unfractionated heparin, due to the lower bleeding and recurrence rates [4]. Therefore, the use of $L M W H$ in the initial phase of acute DVT is an accepted standard in the medical treatment worldwide. According to the ACCP guidelines issued in 200I, the use of LMWH became an alternative for treatment and secondary prophylaxis of acute DVT, especially in patients with contraindications for oral anticoagulants [3, 5-7]. Good safety profile, its efficacy and easy laboratory control enabled the use of LMWH in ambulatory treatment, which was proven in many clinical trials [8-16].
Table 2. The incidences of VTE recurrence, adverse events and symptoms

\begin{tabular}{|c|c|}
\hline VTE recurrence, adverse events and symptoms & $\mathrm{N}(\%)$ \\
\hline \multicolumn{2}{|l|}{ Reccurence of $\mathbf{D V} \mathbf{T}^{\mathbf{a}}$} \\
\hline Yes & $0(0)$ \\
\hline No & $50(100)$ \\
\hline \multicolumn{2}{|l|}{ Pulmonary embolism } \\
\hline Yes & $0(0)$ \\
\hline No & $50(100)$ \\
\hline \multicolumn{2}{|l|}{ Death } \\
\hline Yes & $0(0)$ \\
\hline No & $50(100)$ \\
\hline \multicolumn{2}{|l|}{ Serious bleeding ${ }^{\mathrm{b}}$} \\
\hline Yes & $0(0)$ \\
\hline No & $50(100)$ \\
\hline \multicolumn{2}{|l|}{ Small bleeding ${ }^{c}$} \\
\hline Yes (small hematoma) & $8(16)$ \\
\hline No & $42(84)$ \\
\hline \multicolumn{2}{|l|}{ Heparin induced thrombocytopenia } \\
\hline Yes & $0(0)$ \\
\hline No & $50(100)$ \\
\hline \multicolumn{2}{|l|}{ Repeated hospitalization } \\
\hline Yes & $0(0)$ \\
\hline No & $50(100)$ \\
\hline \multicolumn{2}{|l|}{ Discontinue nadroparine therapy } \\
\hline Yes & $0(0)$ \\
\hline No & $50(100)$ \\
\hline \multicolumn{2}{|l|}{ Local pain ${ }^{d}$} \\
\hline Yes & $6(12)$ \\
\hline No & $44(88)$ \\
\hline \multicolumn{2}{|l|}{ Itching ${ }^{e}$} \\
\hline Yes & $9(18)$ \\
\hline No & $4 I(82)$ \\
\hline \multicolumn{2}{|l|}{ Tolerance of therapy } \\
\hline Yes & $47(94)$ \\
\hline No & $3(6)$ \\
\hline
\end{tabular}

${ }^{\mathrm{a}}$ Deep vein thrombosis

berious bleeding (with changes in blood pressure and hematocrite reduction): gastrointestinal bleeding, vaginal and urological bleeding, intracranial and/or

CUN bleeding, retroperitoneal space bleeding, large subcutaneous or intramuscular hematomas measuring $>4 \mathrm{~cm}$ in diameter

${ }^{c}$ Small bleeding (without changes in blood pressure and hematocrite): heamaturia, the presence of blood in the stool, nose and gingival bleeding, local in bleeding at injection site, small subcutaneous and/or intramuscular hematomas measuring $<4 \mathrm{~cm}$ in diameter

Pain in place of injection

$\mathrm{e}_{\text {Itching in place of injection }}$ 
The present study, which included 50 patients with acute venous thrombosis treated in an ambulatory regimen for three months with calcium nadroparine, revealed very good clinical effects, and no episodes of recurrence. No deaths, nor major treatment-related complications (major bleedings, HIT) were reported. Only 8 (16\%) patients suffered sporadically from small haematomas in the injection site, which was probably related to injection technique. None of the patients required the discontinuation of calcium nadroparine treatment or hospital admission related to treatment. The incidence of local ailments (pain, burning sensation) during injection was small. The tolerance and acceptation for the described therapy were high (94\%).

According to the Canadian study published in 1996 by Levine and TANSMAN trial designed by Koopman, the results of acute DVT treatment were similar between the hospitalised patients and those treated on an out-patient basis. No significant differences concerning the bleeding complications were observed between these groups, as well $[7,8]$. Similar conclusions were reported by Lindmarker et al., who treated about $80 \%$ of their patients with venous thrombosis in the ambulatory setting [9]. Partsch and Blättler reported the faster rate of resolution of pain and swelling when the patients with acute proximal DVT, treated with LMWH, were encouraged to walk and ambulated with compression [10]. The treatment outcome of patients with VTE who performed the subcutaneous injections by themselves at home were reported by Wells et al. and Harrison et al. in 1998 [1I, 12]. The treatment results concerning disease recurrence in the follow-up period, with low bleeding risk and death rate in the hospitalised patients were similar and were $4 \%$ and $6 \%$, respectively. Łopaciuk et al. in 1999 did not observe any difference between calcium nadroparine and acenocumarol in terms of VTE recurrence or bleeding and death [13]. Good outcome of ambulatory treatment with calcium nadroparine and three-month secondary prophylaxis, with lower bleeding rate was reported by Schwarz in 200 I [14]. Many clinical trials proved that this treatment method not only reduces the ambulatory treatment cost, but may reduce the risk of bleeding complication associated with oral anticoagulants [15-19]. Nowadays, the ambulatory treatment of VTE is fully accepted by the medical societies of many Western European countries, and is administered to up to $80 \%$ of patients with venous thrombosis and $50 \%$ of patients with pulmonary embolism [20]. The newly published papers indicate the role of LMWH in the recanalisation of the thrombotic veins and the reduction of valvular incompetence rate, secondary to venous thrombosis $[2 I-29]$.
The presented clinical trial revealed after 3 months of calcium nadroparine treatment a very high rate of good treatment outcome, such as total ( $80 \%$ of patients) or partial ( $20 \%$ of subjects) recanalisation of thrombosed deep vein segments. The function of the valvular apparatus in the recanalised veins was normal in $60 \%$ (30) of patients, and slightly impaired in $40 \%$ (20 subjects).

Lopez-Beret et al. suggest that low-molecular-weight heparins induce the fibrinolytic mechanisms within the venous endothelium [26]. The issue of selecting the treatment method and secondary prophylaxis in VTE is raised by the authors of few multi-centre studies. They suggest that according to the obtained results, the prolonged use of LMWH in therapeutic doses (up to 3 or even 6 months) in patients with venous thrombosis does not significantly increase the risk of bleeding, and is more beneficial than OAs administered traditionally in the secondary prophylaxis [26-29]. They emphasise the fact, that patient groups treated with LMWH, in whom the recanalisation of thrombotic veins was relatively quick, reveal lower incidence of valvular incompetence in the form of reflux and venous insufficiency. The present paper emphasises the role of LMWH in the ambulatory treatment and secondary prophylaxis of VTE, showing their superiority over the vitamin $\mathrm{K}$ antagonists.

The literature data suggests that the treatment with LMWH is associated with less episodes of VTE recurrence, pulmonary embolism, deaths with concomitant lower risk of complications and with better recanalisation rate of thrombosed deep vein segments and preservation of valvular function [15, 20, 25-42].

\section{Conclusions}

Our study confirmed that calcium nadroparine is an efficient, safe and well tolerated method of ambulatory treatment and secondary prophylaxis of the acute, symptomatic deep vein thrombosis of the lower extremities. Further, longer and prospective, multi-centre studies are required for better evaluation of the early and late results of DVT treatment with LMWH. They would allow investigating their effect on venous recanalisation, its function and prevention of post-thrombotic syndrome.

\section{Conflict of interest}

The study concerning the efficacy and safety of calcium nadroparine in the ambulatory treatment and secondary DVT prophylaxis was sponsored by Sanofi. The author has given lectures for physicians, which were sponsored by Sanofi as well. 


\section{References}

I. Hull R, Hirsh J, Raz R et al (1982) Different intensities of oral anticoagulant therapy in the treatment of proximal vein thrombosis. N Engl J Med; 307: 1676-1681.

2. Kuijer PM, Hutten BA, Prins MH et al (1999) Prediction of the risk of bleeding during anticoagulant treatment for venous thromboembolism. Arch Intern Med; I59: 457-460.

3. Hettiarachchi RJK, Prins MH, Lensing AWA et al (1998) Low molecular weight heparin versus unfractioned heparin in the initial treatment of venous thromboembolism. Curr Op Pulm Med; 4: 220-225.

4. der Heijen JF, Hutten BA, Buller HR, Prins MH (2000) Vitamin $\mathrm{K}$ antagonist or low-molecular-weight heparin for the long term treatment of symptomatic venous thromboembolism. Cochrane Database Syst Rev; 4: CD00200I.

5. Hirsh J, Raschke R (2004) Heparin and LMWH: The seventh ACCP Conference on Antithrombotic and Thrombolytic Therapy. Chest; 126: 188S-203S.

6. Buller HR, Agnelli G, Hull R et al (2004) Antithrombotic therapy for venous thromboembolic disease: the Seventh ACCP Conference on Antithrombotic and Thrombolytic Therapy. Chest; 126: 40IS-428S.

7. Levine M, Gent M, Hirsh J et al (1996) A comparison of low-molecular-weight heparin administered primarily at home with unfractioned heparin administered in hospital for proximal deepvein thrombosis. N Engl J Med; 334: 677-68I.

8. Koopman MM, Prandoni P, Piovella F et al (1997) Treatment of venous thrombosis with intravenous unfractioned heparin administered in the hospital as compared with subcutaneous low-molecular-weight heparin administered at home. The Tasman Study Group. N Engl J Med; 337: I25।.

9. Lindmarker P, Holstrom M (1996) Use of LMWH (dalteparin) once daily for the treatment of deep vein thrombosis. A feasibility and health economic study in on outpatient setting. Swedish Venous Thrombosis Dalteparin Trial Group. J Intern Med; 240: 395-40I.

10. Partsch H, Blättler W (2000) Compression and walking versus bed rest in the treatment of proximal deep venous thrombosis with low molecular weight heparin. J Vasc Surg; 32: 86I-869.

II. Wells PS, Kovacs MJ, Bormanis J et al (1998) Expanding eligibility for outpatient treatment of deep venous thrombosis and pulmonary embolism with low-molecular-weight heparin a comparison of patient self-injection with home-care injection. Arch Intern Med; 158: 1809-1812.

12. Harrison L, McGinnis J, Crowther M et al (1998) Assessment of outpatient treatment of deep-vein thrombosis with low-molecular-weight heparin. Arch Intern Med; I58: 200I-2003.

13. Łopaciuk S, Bielska-Fałda H, Noszczyk W et al (1999) Porównanie skuteczności heparyny drobnocząsteczkowej i acenokumarolu we wtórnej profilaktyce zakrzepicy żył głębokich. Thromb Haemost; 81: 26-31.

14. Schwarz T, Schmidt B, Hohlein U et al (200I) Eligibility for home treatment of deep vein thrombosis: prospective study. BMJ; 322: $1212-1213$.

15. Boccalon H, Elias A, Chale JJ et al (2000) Clinical outcome and cost of hospital vs home treatment of proximal deep vein thrombosis with low-molecular-weight heparin. The Vascular Midi-Pyrenees Study. Arch Intern Med; 160: 1769-1773.
16. Lapidus L, Borretzen J, Fahlen $M$ et al (2002) Home treatment of deep vein thrombosis. An out-patient treatment model with once daily injection of low-molecular-weight heparin (tinzaparin) in 555 patients. Patophysiol Haemost Thromb; 32: 59-66.

17. Tillman DJ, Charland SL, Witt DM et al (2000) Effectiveness and economic impact associated with a program for outpatient management of acute deep vein thrombosis in a group model health maintenance organization. Arch Intern Med; 160: 2926-2932.

18. Gomez-Outes A, Rocha E, Martinez-Gonzalez J et al (2006) Cost effectiveness of bemiparin sodium versus unfractioned heparin and oral anticoagulants in the acute and long-term treatment of deep vein thrombosis. Pharmacoeconomics; 24: 81-92.

19. Alonso Martinez JL, Abinzano Guillen ML, Urbieta Echezarreta MA et al (2008) Low-molecular-weight heparin without oral anticoagulants for the treatment of DVT. Ann Med Intern; 25: 4-8.

20. Veiga F, Escriba A, Maluenda MP et al (2000) Low molecular weight heparin (enoxaparin) versus oral anticoagulant therapy (acenocumarol) in the long-term treatment of deep venous thrombosis in the elderly: a randomized trial. Thromb Haemost; 84: 559-564.

21. Gonzalez-Fajardo JA, Arreba E, Castrodeza J et al (1999) Venographic comparison of subcutaneous low-molecular-weight heparin with oral anticoagulant therapy in the long treatment of deep venous thrombosis. J Vasc Surg; 30: 283-292.

22. Breddin HK, Hach-Wunderle V, Nakov R, Kakkar W (200I) CORTES Investigators. Clivarin: Assessment of Regression of Thrombosis, Efficacy and Safety. Effects of a low-molecular weight heparin on thrombus regression and recurrent thromboembolism in patients with deep vein thrombosis. $\mathrm{N}$ Engl J Med; I: 626-63I.

23. Torio A, Guerescin F, Pini M (2003) Low-molecular-weight heparin for the long-term treatment of symptomatic venous thromboembolism: meta-analysis of the randomized comparison with oral anticoagulants. J Thromb Hemost; I: 1906-1913.

24. Romera A, Cairols MA, Vila-Coll R et al (2009) A randomised open-label trial comparing long-term sub-cutaneus low-molecular-weight heparin compared with oral anticoagulant therapy in the treatment of deep venous thrombosis. Eur J Vasc Endovasc Surg; 37: 349-356.

25. Vorob'eva NM, Panchenko EP, Ermolina OV et al (20I I) Prolongation of enoxaparin therapy to one month promotes recanalization of the occlusively thrombosed deep veins. Ter Arkh; 83: 33-37.

26. Lopez-Beret P, Orgaz A, Foncuberta J et al (200I) Low molecular weight heparin versus oral anticoagulants in the long-term treatment of deep venous thrombosis. J Vasc Surg; 33: 77-90.

27. Pini M, Aiello S, Manotti $C$ et al (200I) Low molecular weight heparin versus warfarin in the prevention of recurrences after deep venous thrombosis. J Vasc Surg; 33: 77-90.

28. Lyman GH, Khorana AA, Falanga A et al (2007) American Society of Clinical Oncology guideline: recommendations for venous thromboembolism prophylaxis and treatment in patients with cancer. J Clin Oncol; 25: 5490-5505.

29. Ferretti G, Bria E, Giannerelli D et al (2006) Is recurrent venous thromboembolism after therapy reduced by low-molecular-weight heparin compared with oral anticoagulants? Chest; 130: 1880-1816.

30. Daskalopoulos ME, Daskalopoulou SS, Tzortis E et al (2005) Long-term treatment of deep venous thrombosis with a low 
molecular weight heparin (tanzaparin): a prospective randomized trial. Eur J Vasc Surg; 29: 638-650.

31. Romera-Villegas A, Cairols-Castellote MA, Vila-Coll R et al (2010) Long-term use of different doses of low-molecular-weight heparin versus vitamin $\mathrm{K}$ antagonist in the treatment of venous thromboembolism. Ann Vasc Surg; 24: 628-639.

32. Gonzalez-Fajardo JA, Martin-Pedrosa M, Castrodeza J et al (2008) Effect of the anticoagulant therapy in the incidence of post-thrombotic syndrome and recurrent thromboembolism: comparative study of enoxaparin versus coumarin. J Vasc Surg; 48: 953-959.

33. Gomez-Outes A, Lecumberri R, Lafuente-Guijosa A et al (2004) Correlation between thrombus regression and recurrent venous thromboembolism. Examining venographic and clinical effects of low-molecular-weight heparin: a meta-analysis. J Thromb Haemost; 2: I58I-I587.

34. Hirsh J, Guyatt G, Albers GW et al (2008) Antithrombotic and Thrombolytic Therapy: American College of Chest Physicians Evidence-Based Clinical Practice Guidelines (8th Edition). Chest; I33 (6 suppl): | |0-| |2.

35. Wakefield TW, McLafferty RB, Lohr JM et al (2009) Call to action to prevent venous thromboembolism. J Vasc Surg; 49: 1620-1623.
36. 36. Goldhaber SZ (200I) Epidemiology of pulmonary embolism. Semin Vasc Med; I: 139-146.

37. Bateman AG, Sheaff R, Child S et al (2013) The implementation of nice guidance on venous thromboembolism risk assessment and prophylaxis: a before-after observational study to assess the impact on patient safety across four hospitals in England. BMC Health Sero Res; 13: 203.

38. Johansson M, Johansson L, Limd M (2014) Incidence of venous thromboembolism in northern Sweden (VEINS): a population-based study. Thromb J; 12: 6 .

39. Kahn SR, Ginsberg JS (2004) Relationship between deep venous thrombosis and the postthrombotic syndrome. Arch Intern Med; 164: 17-26.

40. Tullett J, Murray E, Nichols L et al (2013) Trial Protocol: A randomized controlled trial of extended anticoagulation treatment versus routine anticoagulation treatment for the prevention of recurrent VTE and postthrombotic syndrome in patients being treated for a first episode of unprovoked VTE (The ExACT Study). BMC Cardiovasc Dis; 13: 16.

4I. Prandoni P, Lensing AW, Cogo A et al (1996) The long term clinical course of acute deep venous thrombosis. Ann Intern Med; 125: I-7.

42. Ruckley CV (1997) Socioeconomic impact of chronic venous insufficiency and leg ulcers. Angiology; 48: 67-69. 